\title{
Sulphonylurea therapy doubles B-cell response to glucose in Type 2 diabetic patients
}

\author{
J.P. Hosker, M. A. Burnett, E. G. Davies, E. A. Harris and R. C. Turner \\ Diabetes Research Laboratories, Radcliffe Infirmary, Oxford, UK
}

Summary. The effect of sulphonylurea therapy for 3 weeks on glucose-stimulated insulin secretion and insulin resistance was studied in Type 2 diabetic patients. The fasting plasma insulin and C-peptide concentrations on diet alone were compared with each subject's fasting concentrations on sulphonylurea treatment at a lower fasting plasma glucose and at the original diet-alone glycaemic level obtained by the hyperglycaemic clamp technique. At this isoglycaemic level (mean $11 \mathrm{mmol} / \mathrm{l}$ ), plasma insulin levels increased from $6.9 \mathrm{mU} / 1$ on diet alone to $12.1 \mathrm{mU} / 1$ on sulphonylurea treatment $(p<0.01)$. The subjects were also studied by the hyperglycaemic clamp technique at mean glycaemic levels of $13 \mathrm{mmol} / 1$ before and after sulphonylurea treatment; the incremental insulin re- sponse was similarly enhanced from $7.6 \pm 3.5$ to $13.7 \pm$ $6.9 \mathrm{mU} / 1(p<0.02)$ respectively. Sulphonylureas appear to reduce glycaemia by enhancing B-cell function two-fold. In the patients studied this was from approximately $21 \%$ to $37 \%$ of a normal response. Insulin resistance assessed by the same hyperglycaemic clamps as endogenous plasma insulin concentrations divided by glucose infusion rates was unchanged by sulphonylurea therapy (mean 4.37 compared to $4.40 \mathrm{mU}$. $\mathrm{l}^{-1} \cdot \mathrm{mg}^{-1} \cdot \mathrm{kg} \cdot \min$ on diet alone).

Key words: Sulphonylureas, insulin, C-peptide, insulin resistance, hyperglycaemic clamp.
Sulphonylurea drugs have been used in the treatment of Type 2 (non-insulin-dependent) diabetes for over 20 years, but there is still controversy concerning the precise mode of the hypoglycaemic action of these drugs. Although some studies show enhanced insulin responses [1-4], others have suggested that fasting and stimulated plasma insulin levels do not change during the chronic administration of sulphonylurea therapy [5-11]. These studies have not taken into account that the same plasma insulin, stimulated by a lower post-sulphonylurea-treatment plasma glucose level, may represent an improvement in B-cell function. Intravenous tolbutamide has been shown to have a greater effect on enhancing the insulin response to non-glucose stimuli when the fasting plasma glucose concentration has been maintained [12]. In these previous studies B-cell function and insulin resistance have been assessed as independent phenomena on separate occasions.

We compared B-cell function in Type 2 diabetic patients before and after sulphonylurea treatment by studying them at the same plasma glucose concentrations with the hyperglycaemic clamp technique [13]. This also provided a simultaneous measure of insulin resistance with regard to endogenous insulin secretion, and allowed examination of the extra-pancreatic effects of sulphonylurea drugs.

\section{Subjects and methods}

\section{Subjects}

Ten Type 2 diabetic patients were studied, aged $42-69$ years, with duration of diabetes 1-32 years, and body mass index 21.6-29.7 (Table 1). Seven patients were on the recommended maximal sulphonylurea dose, six being treated with chlorpropamide $(125-500 \mathrm{mg}$ daily as a single morning dose), and four with glibenclamide

Table 1. Characteristics of subjects studied

\begin{tabular}{lllll}
\hline Subject & $\begin{array}{l}\text { Age } \\
\text { (years) }\end{array}$ & $\begin{array}{l}\text { Body mass } \\
\text { index } \\
\left(\mathrm{kg} / \mathrm{m}^{2}\right)\end{array}$ & $\begin{array}{l}\text { Duration } \\
\text { of diabetes } \\
\text { (years) }\end{array}$ & Drug (daily dose) \\
\hline 1 & 69 & 26.5 & 32 & Glibenclamide $2.5 \mathrm{mg}$ \\
2 & 66 & 24.1 & 4 & Chlorpropamide $500 \mathrm{mg}$ \\
3 & 55 & 23.1 & 3 & Chlorpropamide $125 \mathrm{mg}$ \\
4 & 42 & 24.8 & 2 & Chlorpropamide $500 \mathrm{mg}$ \\
5 & 55 & 23.0 & 1 & Chlorpropamide $250 \mathrm{mg}$ \\
6 & 52 & 21.6 & 1 & Chlorpropamide $500 \mathrm{mg}$ \\
7 & 50 & 26.0 & 2 & Glibenclamide $20 \mathrm{mg}$ \\
8 & 66 & 22.7 & 10 & Chlorpropamide $500 \mathrm{mg}$ \\
9 & 55 & 25.0 & 1 & Glibenclamide $20 \mathrm{mg}$ \\
10 & 44 & 29.7 & 12 & Glibenclamide $20 \mathrm{mg}$ \\
\hline
\end{tabular}

Note: 1 and 9 were female, remaining subjects were male 


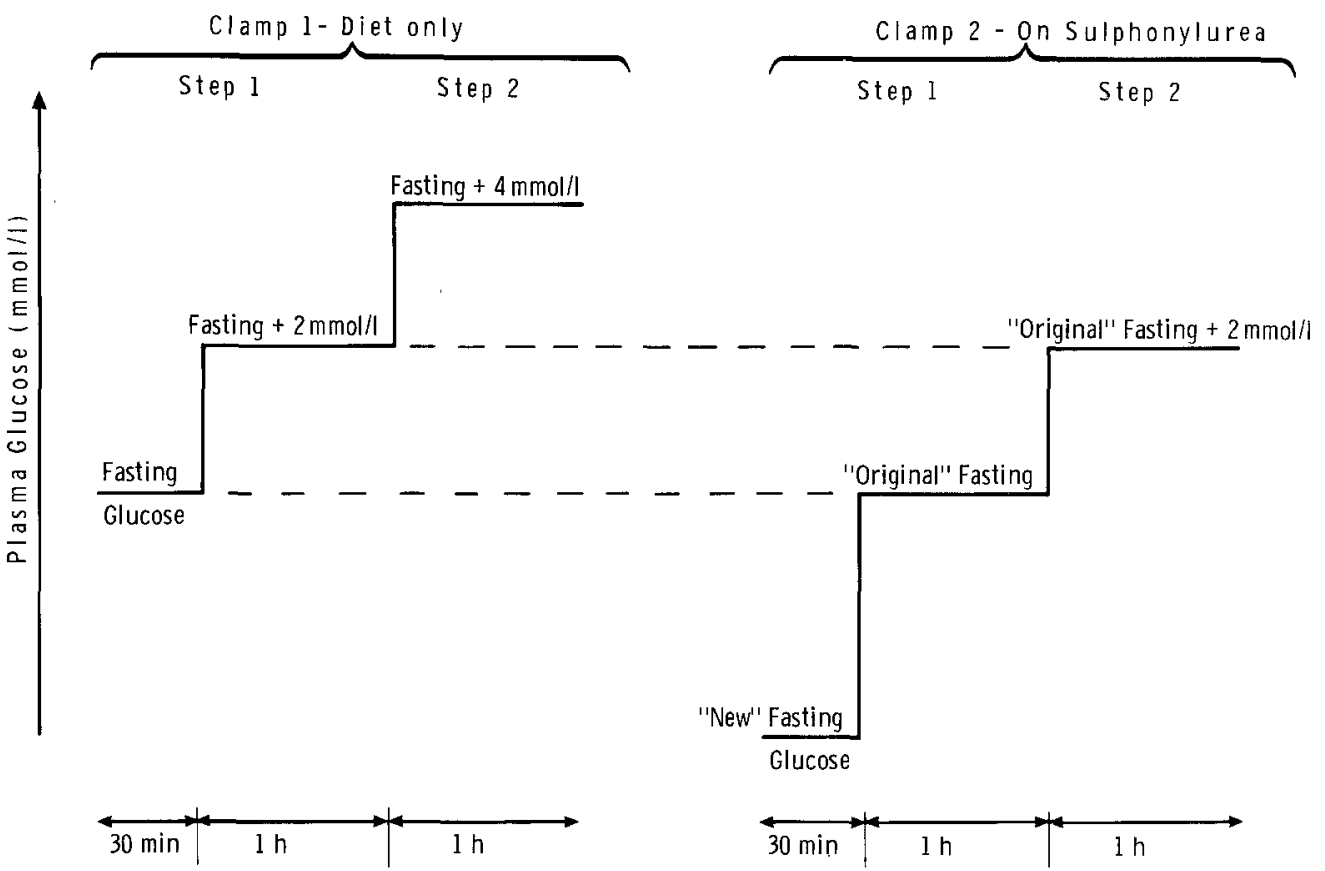

Fig. 1. Design of the study, showing the relative plasma glucose concentrations during the different hyperglycaemic clamps
(2.5-20 mg daily in divided morning and evening doses). All subjects were on a weight-maintaining diet including at least $200 \mathrm{~g}$ of carbohydrate/day. The subjects stopped taking their oral hypoglycaemic agents for a 3-week period, at the end of which they fasted for their first hyperglycaemic clamp study. They then resumed taking their normal oral agents at the usual dosage, and had a second hyperglycaemic clamp study performed after a further 3 weeks.

For a comparison with the equivalent non-diabetic insulin and Cpeptide levels, six normal subjects, aged 41-69 years, body mass index 22.1-26.6, were studied by hyperglycaemic clamp at $10 \mathrm{mmol} / 1$ for $1 \mathrm{~h}$. Mean plasma insulin and C-peptide levels were calculated over the last $30 \mathrm{~min}$.

\section{Study design}

The design of the study is summarized in Figure 1 . The first hyperglycaemic clamp study, at the end of week 3 off oral hypoglycaemic agents, consisted of a 30 -min sampling period at the fasting plasma glucose level ('original' fasting glucose), followed by a hyperglycaemic clamp at $2 \mathrm{mmol} / 1$ above the fasting plasma glucose for $1 \mathrm{~h}$ followed by a hyperglycaemic clamp at $4 \mathrm{mmol} / 1$ above the fasting plasma glucose for a further hour. The second clamp study, after 3 weeks on the patient's usual sulphonylurea therapy, consisted of a 30-min sampling period at the new lower fasting plasma glucose, followed by a hyperglycaemic clamp for $1 \mathrm{~h}$ at the level of the original fasting plas. ma glucose from the first study on diet therapy alone, followed by a hyperglycaemic clamp for $1 \mathrm{~h}$ at $2 \mathrm{mmol} / 1$ above the original fasting plasma glucose from the first study.

Subjects came to the hospital in the morning for a test, having fasted from $22.00 \mathrm{~h}$. During the clamps, continuous 2-min samples were taken through a double lumen cannula, heparinized at the tip by retrograde infusion of heparin through the outer concentric/umen of the cannula (1/100 volume of the blood sample) to achieve a final concentration in the sample of $50 \mathrm{U}$ heparin $/ \mathrm{ml}$. This cannula was placed in a distal vein of a forearm which had been warmed with an electric heating pad. A second teflon cannula was placed in an ipsilateral antecubital vein for glucose infusion. For prediction of the glucose infusion rates required to maintain hyperglycaemia, an iterative learning program was used on a Apple IIe microcomputer. To achieve a new level of hyperglycaemia, a bolus of $50 \mathrm{~g} / \mathrm{dl}$ glucose solution of a size suggested by the program was infused. The subsequent $2 \mathrm{~min}$ blood samples taken were analysed for plasma glucose using a glucose-oxidase method (Glucose Analyzer 2, Beckman Instruments, Fullerton California, USA), and the program supplied the infusion rate of $10 \mathrm{~g}$ / dl glucose solution required to maintain the target level of hyperglycaemia. Glycosuria was measured at the end of the clamp with the Beckman analyser. Subjects were fed promptly to avoid reactive hypoglycaemia.

\section{Laboratory methods}

Samples were assayed for insulin using a charcoal-phase separation method [14] with antibody kindly provided by Professor P. Sonksen, St.Thomas's Hospital, London, and for C-peptide using a similar method [15] with reagents from a kit including antibody M1230 (Novo Industri, Copenhagen, Denmark). The normal fasting plasma concentrations were $6.0 \pm 3.1 \mathrm{mU} / 1$ insulin and $0.3 \pm 0.14 \mathrm{nmol} / 1 \mathrm{C}$-peptide respectively, and the coefficient of variation of the assays were 13.7 and $9.1 \%$ respectively. No patient had anti-insulin antibodies. The stimulated insulin and C-peptide values were calculated for each new level of hyperglycaemia using the mean value of four samples spaced evenly over the last $30 \mathrm{~min}$ of each hour-long level of hyperglycaemia. Similarly, fasting insulin and C-peptide levels were calculated from four samples evenly spaced over the 30 -min fasting sampling period. Insulin resistance was calculated, for the diet-only and the sulphonylurea-treatment hyperglycaemic clamp studies, by dividing the steadystate plasma insulin over the last 30min of the second hyperglycaemic step by the mean glucose infusion value over the same time $(\mathrm{mU}$. $\left.\mathrm{l}^{-1} \cdot \mathrm{mg}^{-1} \cdot \mathrm{kg} \cdot \mathrm{min}\right)$. The infusion values were corrected for glycosuria, assuming a steady rate of glycosuria over the two hyperglycaemic steps. A similar value for insulin resistance was calculated, substituting plasma $\mathrm{C}$-peptide for plasma insulin values, to provide a figure independent of any possible extra proinsulin production stimulated by sulphonylurea treatment $\left(\mathrm{nmol} \cdot \mathrm{l}^{-1} \cdot \mathrm{mg}^{-1} \cdot \mathrm{kg} \cdot \mathrm{min}\right)$.

\section{Statistical analysis}

Statistical analyses included paired Student's t-tests for comparison of patient's responses to diet and sulphonylurea therapy.

\section{Results}

Quality of the hyperglycaemic clamps

The range of coefficients of variation of plasma glucose over the last $30 \mathrm{~min}$ of the first hyperglycaemic level for all clamp studies was $0.2-4.7 \%$ (median $2.5 \%$ ). The 


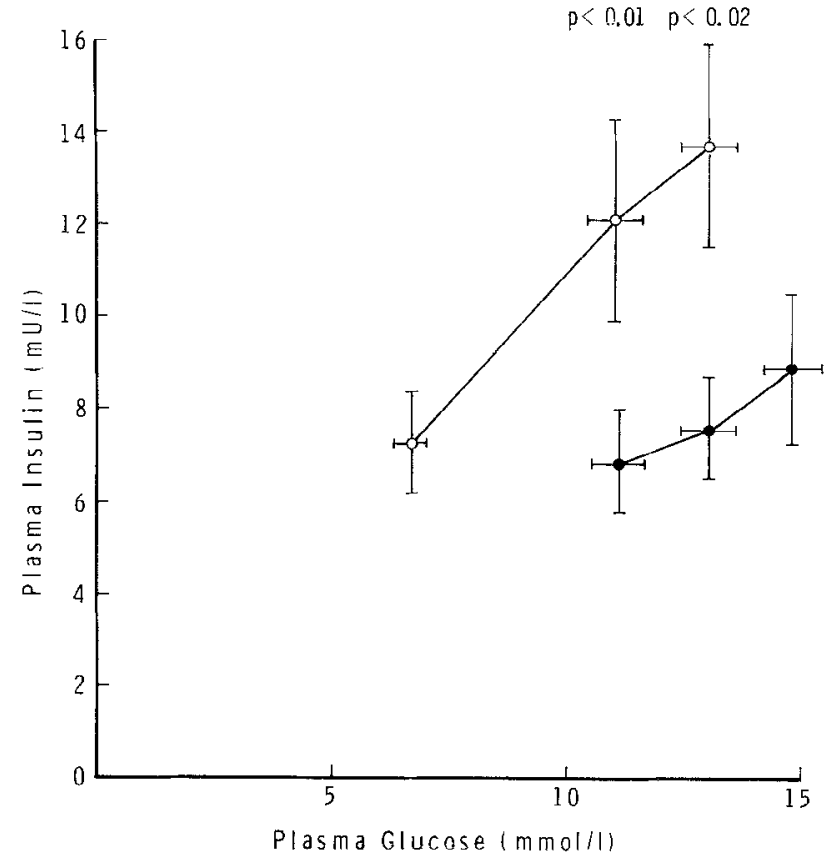

Fig. 2. Mean $\pm S E M$ plasma glucose and insulin concentrations for the diabetic patients on diet only $(-\infty)$ and on diet + sulphonylurea $(\mathrm{O}-\mathrm{O})$ when fasting and during hyperglycacmic clamps

range for the same figure for the second hyperglycaemic level was $1.7-4.5 \%$ (median $2.6 \%$ ). The ranges of coefficients of variation of plasma insulin over the last $30 \mathrm{~min}$ of the first and second levels of hyperglycaemia for all clamps were $0.2-30 \%$ (median $14.7 \%$ ) and $2.9-22.7 \%$ (median 9.8\%) respectively.

\section{Plasma glucose concentrations}

The mean fasting plasma glucose level was reduced from $11.1 \mathrm{mmol} / 1$ on diet alone to $6.7 \mathrm{mmol} / 1$ on diet and sulphonylurea (Table 2). In line with the design of the experiment, the mean \pm SD of the first hyperglycaemic step on sulphonylurea, $(11.0 \pm 2 \mathrm{mmol} / \mathrm{l})$ was similar to the plasma glucose level at the original fasting plasma glucose on diet alone. The plasma glucose levels from the second hyperglycaemic step on sulphonylurea and the first hyperglycaemic step on diet were $13.0 \pm 2$ and $13.0 \pm 1.9 \mathrm{mmol} / 1$ respectively.

\section{Plasma insulin and C-peptide concentrations}

The plasma insulin and C-peptide results are shown in Table 2. The mean fasting plasma insulin levels on diet and sulphonylurea were 6.9 and $7.3 \mathrm{mU} / 1$ respectively $(p>0.1)$, and the fasting $C$-peptide levels were 0.43 and $0.49 \mathrm{nmol} / \mathrm{ml}$ respectively $(p>0.1)$.

Mean B-cell glucose-insulin stimulus-response curves before and after treatment with the sulphonylurea are shown in Figure 2. When the comparison was made at the same original fasting plasma glucose concentration, the plasma insulin values were $6.9 \pm 3.7$ and 
$12.1 \pm 7.1 \mathrm{mU} / 1$ on diet and sulphonylurea respectively $(p<0.01)$. During the hyperglycaemic clamp studies at $2 \mathrm{mmol} / \mathrm{l}$ above the original fasting plasma glucose, the plasma insulin concentrations were $7.6 \pm 3.5$ and $13.7 \pm 6.9 \mathrm{mU} / 1$ respectively $(p<0.02)$. The percentage increases in the mean insulin levels at the two levels were $75 \%$ and $80 \%$ respectively.

Mean B-cell glucose-C-peptide stimulus-response curves on diet only and on sulphonylurea treatment are

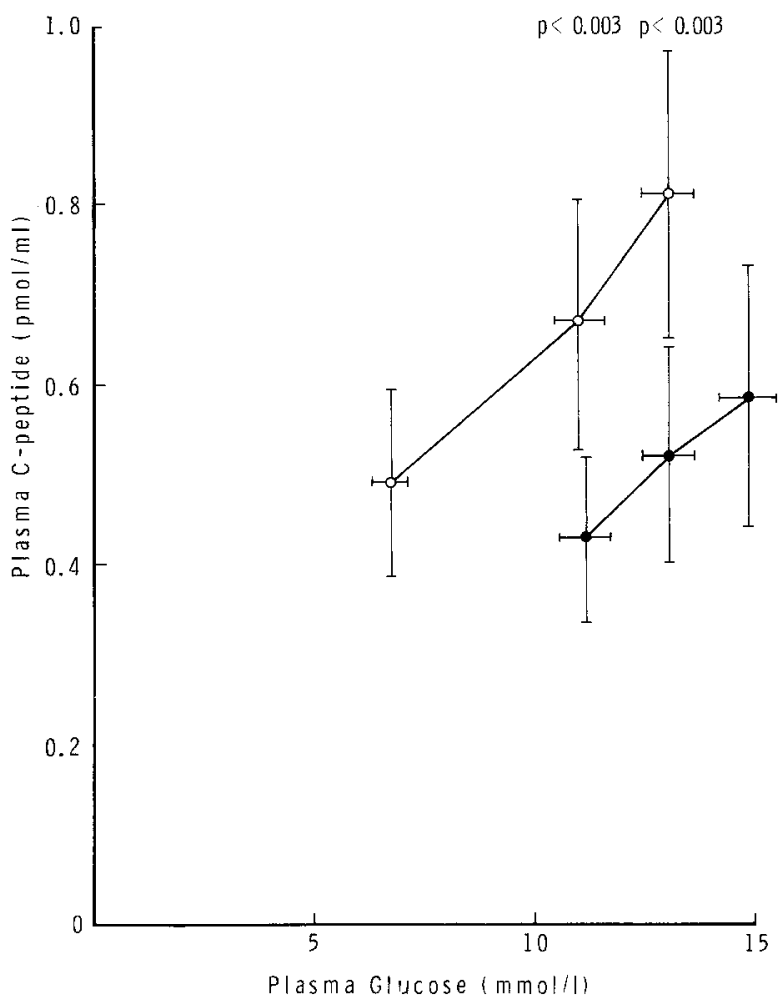

Fig. 3. Mean \pm SEM plasma glucose and C-peptide concentrations for the diabetic patients on diet only $(-\infty)$ and on diet + sulphonylurea $(\mathrm{O}-\mathrm{O})$ when fasting and during hyperglycaemic clamps shown in Figure 3. The mean \pm SD of plasma C-peptide level at original fasting plasma glucose concentrations (for the fasting state on diet alone and the first hyperglycaemic step on sulphonylurea) were $0.43 \pm 0.3$ and $0.67 \pm 0.44 \mathrm{nmol} / 1$ respectively $(p<0.003)$. Similarly, the C-peptide levels during the hyperglycaemic clamps at $2 \mathrm{mmol} / 1$ above the diet alone fasting plasma glucose level were $0.52 \pm 0.37$ and $0.81 \pm 0.5 \mathrm{nmol} / 1$ during diet only and sulphonylurea treatment respectively $(p<0.003)$ (Fig. 3). The percentage increase in the mean C-peptide concentration was $56 \%$ at both plasma glucose concentrations. The patients on glibenclamide and chlorpropamide had similar glucose and B-cell response.

The six normal subjects had a mean plasma insulin of $33 \mathrm{mU} / 1$ and mean plasma C-peptide of $2.2 \mathrm{nmol} / 1$ over the last $30 \mathrm{~min}$ of the $10 \mathrm{mmol} / 1$ hyperglycaemic clamp.

\section{Insulin resistance}

The mean \pm SD insulin resistance values derived from the second hyperglycaemic step for all subjects on diet only and on sulphonylurea treatment were similar $\left(4.40 \pm 2.71\right.$ and $4.37 \pm 2.11 \mathrm{mU} \cdot 1^{-1} \cdot \mathrm{mg}^{-1} \cdot \mathrm{kg} \cdot \mathrm{min}$ respectively) (Table 2). The equivalents for insulin resistance, using the C-peptide values from the second hyperglycaemic step, were $0.31 \pm 0.23$ and $0.27 \pm 0.17$ $\mathrm{nmol} \cdot 1^{-1} \cdot \mathrm{mg}^{-1} \cdot \mathrm{kg} \cdot \mathrm{min}$ respectively.

\section{Discussion}

The fasting plasma insulin and C-peptide concentrations were not significantly higher on sulphonyurea therapy than on diet alone, although other studies have reported significantly increased fasting C-peptide levels on sulphonylurea treatment $[3,16]$. This is compatible

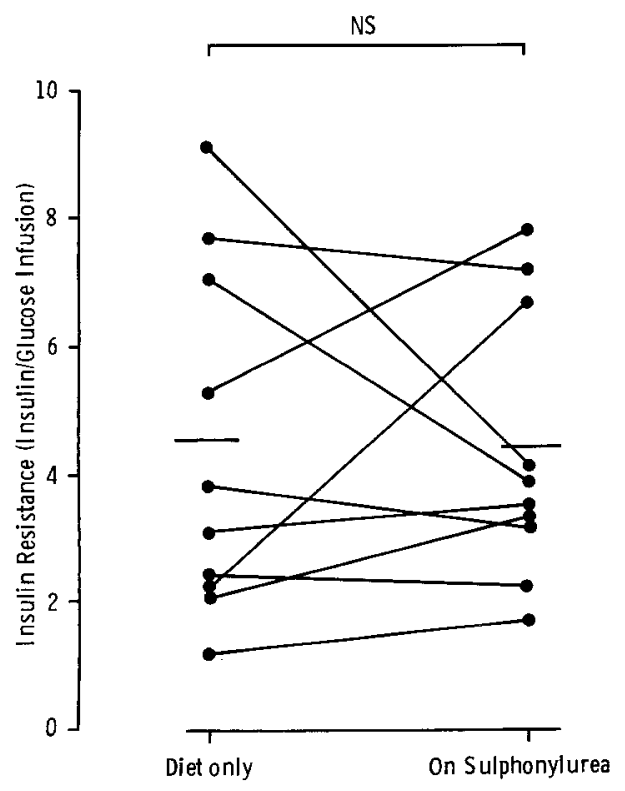

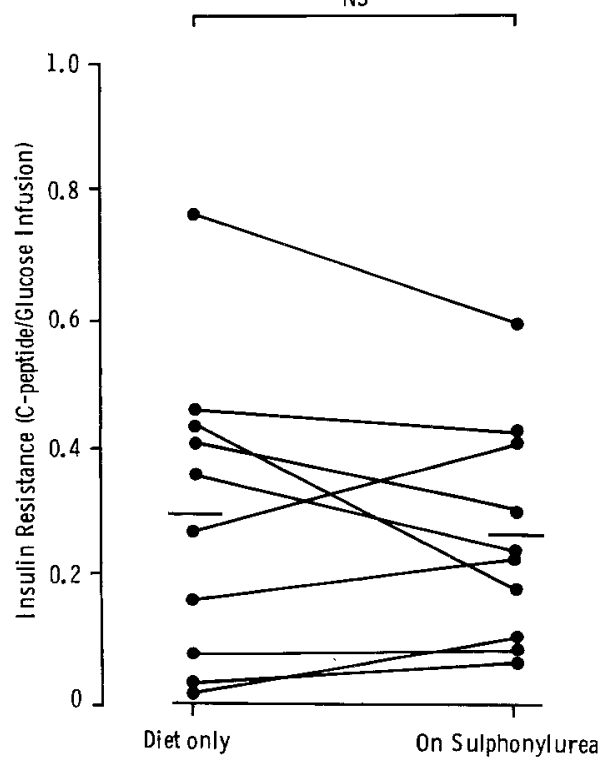

Fig.4. Lack of change in insulin resistance induced by sulphonylurea, measured by relating endogenous plasma insulin or C-peptide concentrations during hyperglycaemic clamp to the glucose infused 
with a slightly reduced basal insulin secretion in Type 2 diabetes being an "error signal" maintaining basal hyperglycaemia [16]. With improved B-cell efficiency, both the hyperglycaemia decreases and the reduced basal insulin level rises. The interplay of glucose and insulin concentrations in a feedback loop makes it difficult to assess from these changes the degree to which B-cell function has been enhanced [17, 18]. When the subjects on sulphonylurea therapy had their plasma glucose raised to the diet-only treatment fasting plasma glucose level, it became apparent that the plasma insulin levels on sulphonylurea were approximately twice those on diet alone. An approximate doubling of plasma insulin levels after sulphonylurea was also found at a standard plasma glucose concentration $2 \mathrm{mmol} / 1$ higher than the original fasting level. The more precise C-peptide assay showed a consistent increase of B-cell secretion on sulphonylureas, although the individual percentage increase of mean C-peptide was less than the insulin rise over $60 \mathrm{~min}$, reflecting the longer $\mathrm{C}$-peptide plasma half-life $[19,20]$ and hence a slower increase in plasma concentration.

Other recent studies have recognized that sulphonylurea increases the insulin response to glucose but none have attempted to quantify the increase [1-4, 21, 22]. The importance of assessing the plasma insulin responses during sulphonylurea treatment, under pretreatment glycaemic conditions, has been shown in the studies of the masking of improved insulin secretion by the lower fasting plasma glucose levels caused by sulphonylurea treatment [23-25]. A more prolonged glucose clamp on sulphonylurea therapy, at the original fasting plasma, glucose concentration on diet only, may have increased plasma insulin levels even further, but this is unlikely to be a marked effect in view of the slight increase in plasma insulin during the second hour at a $2 \mathrm{mmol} / 1$ higher glucose concentration. Although the sulphonylurea at the original fasting plasma glucose on diet enhanced the plasma insulin response from 7 to $12 \mathrm{mU} / \mathrm{l}$, this compares with a mean plasma insulin level of $33 \mathrm{mU} / 1$ after a $60 \mathrm{~min}$ clamp in normal subjects at $10 \mathrm{mmol} / 1$ [26], so the sulphonylurea drugs appear to have boosted the B-cell response to glucose from approximately $21 \%$ to $37 \%$ of the normal response.

The values for insulin resistance were derived from the second hyperglycaemic step in both the diet only and the sulphonylurea treatment hyperglycaemic clamps. This involved comparing insulin resistances at a higher plasma glucose for the hyperglycaemic clamp studies during diet treatment than for the hyperglycaemic clamp during sulphonylurea treatment (mean plasma glucoses 14.8 and $13.0 \mathrm{mmol} / 1$ respectively). Comparison of glucose disposal after the same time interval from the start of both the diet-only and sulphonylureatreated hyperglycaemic clamps is essential, because glucose disposal is strongly related to duration of hyperinsulinaemia; during euglycaemic hyperinsulinaemic clamps the glucose disposal rate doubles after a second hour [13]. Any error inherent in comparing insulin resistances at these slightly different plasma glucose levels is likely to be small because the relationship between plasma glucose and hepatic and peripheral glucose uptake changes little above plasma glucose levels of $12 \mathrm{mmol} / 1$ [27-28]. There was no evidence for altered insulin resistance with sulphonylurea treatment with either the insulin or the C-peptide measures of insulin resistance. Insulin resistance appeared to be more constant for each individual if the C-peptide figure was used, and this reflects the greater precision of this assay.

Many studies have pointed to the existence of extrapancreatic effects of sulphonylureas and have suggested that these effects are clinically important. It is known that sulphonylureas increase insulin-binding to monocytes [29] and hepatocellular membranes [30] in vitro. Sulphonylureas have been noted to improve post-receptor insulin sensitivity in vitro in adipocytes [31] and hepatocytes [32]. Glucose disposal in vivo has been shown to increase in non-diabetic dogs [33] and diabetic patients [21] treated with sulphonylureas when investigated by the euglycaemic hyperinsulinaemic clamp technique. Our study was designed to assess in vivo resistance to endogenous insulin secreted into the portal vein. In comparison, the euglycaemic hyperinsulinaemic clamp assesses resistance at much higher concentrations of exogenous insulin infused into the systemic circulation with loss of the normal high portal to peripheral plasma insulin ratio. Resistance to endogenous insulin, as assessed by the hyperglycaemic clamp, may be more relevant to diabetic patients in the fasting and post-prandial state. The normal plasma glucose levels prevailing during euglycaemic clamps are rarely, if ever, present in diabetes, whereas the fasting and stimulated levels at which diabetic patients have been studied for this protocol reflect typical fasting and post-prandial glucose levels. Similarly, the in vitro studies, although elegant demonstrations of real phenomena, may not be relevant to the day-to-day insulin and glucose levels of diabetes.

Acknowledgements. We are grateful to Mr. E. Bown for skilled assistance, and to Bayer and the Charles Wolfson Charitable Trust for grants.

\section{References}

1. Holman RR, Turner RC (1978) Basal normoglycaemia attained with chlorpropamide in mild diabetes. Metabolism 27:539-547

2. Sonksen PH, Lowy C, Perkins JR, West TET (1981) Hormonal and metabolic effects of chlorpropamide, glibenclamide and placebo in a cross-over study in diabetes not controlled on diet alone. Diabetologia 20: 22-30

3. Elkeles RS, Heding LG, Paisey RB (1982) The long-term effects of chlorpropamide on insulin, C-peptide, and proinsulin secretion. Diabetes Care 4: 427-429

4. Tsalikian E, Dunphy TW, Bohannon NV, Lorenzi M, Gerich JE, Forsham PH, Kane JP, Karam JH (1977) The effect of chronic oral antidiabetic therapy on insulin and glucagon responses to a meal. Diabetes 26:314-321 
5. Seltzer HS, Allen EW, Brennan MT (1965) Failure of prolonged sulfonylurea administration to enhance insulinogenic response to glycemic stimulus. Diabetes 14: 392-395

6. Reaven G, Dray J (1967) Effect of chlorpropamide on serum glucose and insulin concentrations in patients with maturity onset diabetes. Diabetes 16: 487-492

7. Feldman JM, Lebovitz HE (1971) Endocrine and Metabolic effects of glibenclamide. Evidence for an extra pancreatic mechanism of action. Diabetes 20:745-755

8. Duckworth WC, Solomon SS, Kitabchi CJ (1972) Effect of chronic sulphonylurea therapy on plasma insulin and proinsulin levels. J Clin Endocrinol Metab 35: 585-591

9. Barnes AJ, Crowley MF, Garbien KJT, Bloom A (1974) Effect of short and long-term chlorpropamide treatment on insulin release and blood glucose. Lancet 1:69-72

10. Shenfield GM, Logan A, Stirling D, Baird J (1977) Plasma insulin and glucose lipids in maturity onset diabetes treated with chlorpropamide. Diabetologia 13: 367-371

11. Sartor G, Scherten B, Melander A (1978) Effects of glipizide and food intake on the blood levels of glucose and insulin in diabetic patients. Acta Med Scand 203: 211-214

12. Pfeifer MA, Jeffrey B, Halter B, Graf R, Porter D (1980) Potentiation of insulin secretion to nonglucose stimuli in normal man by tolbutamide. Diabetes 29: 335-340

13. DeFronzo RA, Tobin JD, Andres R (1979) Glucose clamp technique: a method for quantifying insulin secretion and resistance. Am J Physiol 237: E214-223

14. Albano JDM, Ekins RP, Maritz G, Turner RC (1972) A sensitive, precise, radioimmunoassay of serum insulin relying on charcoal separation of bound and free hormone moieties. Acta Endocrinol 70: $487-509$

15. Holman RR, Turner RC (1977) Diabetes: the quest for basal normoglycaemia. Lancet 1: 469-474

16. Holman RR, Turner RC (1979) Maintenance of basal plasma glucose and insulin concentration in maturity-onset diabetes. Diabetes 28: $227-230$

17. Turner RC, Holman RR (1976) Insulin rather than glucose homeostasis in the pathophysiology of diabetes. Lancet 1: $1272-1274$

18. Turner RC, Holman RR, Matthews DR, Peto J (1982) Relative contributions of insulin deficiency and insulin resistance in maturity-onset diabetes. Lancet 1: 596-598

19. Faber OK, Kehlet H, Madsbad S, Binder C (1978) Kinetics of human C-peptide in man. Diabetes 27: 207-209

20. Turner RC, Grayburn JA, Newman GB, Nabarro JDN (1971) Measurement of the insulin delivery rate in man. J Clin Endocrinol Metab 33: 279-286

21. Kolterman OG, Gray RS, Shapiro G, Scarlett JA, Griffin J, Olefsky JM (1984) The acute and chronic effects of sulfonylurea therapy in Type II diabetic subjects. Diabetes $33: 346-354$
22. Beck-Nielsen H, Lindskov HO, Richelsen B, Faber O, Binder C (1983) Mechanism of action of glibenclamide in Type 2 (non-insulin-dependent) diabetes during long term treatment. Diabetologia 23: 153 (Abstract)

23. Judzewitsch RG, Pfeifer MA, Best JD, Beard JC, Halter JB, Porte DJ (1982) Chronic chlorpropamide therapy of noninsulin-dependent diabetes augments basal and stimulated insulin secretion by increasing islet sensitivity to glucose. J Clin Endocrin Metab 55: 321-332

24. Pfeifer MA, Halter JB, Porte D (1981) Insulin secretion in diabetes mellitus. Am J Med 70: 579-588

25. Pfeifer MA, Halter JB, Judzewitsch RG, Beard JC, Best JD, Ward WK, Porte D (1984) Acute and chronic effects of sulphonylurea drugs on pancreatic islet cell function in man. Diabetes Care 7:1; 25-34

26. Hosker JP, Burnett MA, Davies EG, Matthews DR, Rudenski A, Turner RC (1984) Loss of normal sigmoid, beta-cell dose-response curve to glucose in non-insulin-dependent diabetes. Diabetologia 27:289 (Abstract)

27. Daniel PM, Love ER, Pratt OE (1975) Insulin stimulated entry of glucose into muscle in vivo as a major factor in the regulation of blood glucose. J Physiol 247: 273-288

28. Kolterman OG, Gray RS, Griffin J, Burstein P, Insel J, Scarlett JA, Olefsky JM (1976) Receptor and postreceptor defects contribute to the insulin resistance in non-insulin-dependent diabetes mellitus. J Clin Invest 68: 957-969

29. Olefsky JM, Reaven GM (1976) Effects of sulfonylurea therapy on insulin binding to mononuclear leukocytes of diabetics patients. Am J Med 60: 89-95

30. Feinglos MN, Lebovitz HE (1978) Sulfonylureas increase the number of insulin receptors. Nature 276: 184-185

31. Maloof BL, Lockwood DH (1981) In vitro effects of a sulfonylurea on insulin action in adipocytes. J Clin Invest 68: 85-90

32. Salhanick AI, Konnowitz P, Amatruda JM (1983) Potentiation of insulin action by a sulfonylurea in primary cultures of hepatocytes from normal and diabetic rats. Diabetes 32: 206-212

33. Putnam WS, Anderson DK, Jones RS, Lebovitz HE (1981) Selective potentiation of insulin-mediated glucose disposal in normal dogs by the sulfonylurea glipizide. J Clin Invest 67: 1016-1023

Received: 11 January 1985

in revised form: 26 September 1985

Dr. R. C. Turner

Diabetes Research Laboratories

Radcliffe Infirmary

Woodstock Road

Oxford OX2 6HE

UK 